\title{
Asset Management Optimization Through Integrated Systems Thinking and N-1 Contingency Capability for Refurbishment
}

\author{
Burnet O'Brien Mkandawire, Nelson Mutatina Ijumba, Member, IEEE, and Howard Whitehead
}

\begin{abstract}
This paper presents a systems view of refurbishment systems to evaluate root causes of suboptimal refurbishment. Case studies from ten selected South African and Malawian fi rms from largest electric power utilities, mining, petrochemical, and processing industries were used to establish causal relationships. Sample surveys of thirty four Malawian firms were used as part of a multimethod or triangulation approach to provide generaliza-tions, validation and reliability. Of the surveyed firms, $66.7 \%$, and of case studied fi rms $100 \%$, showed that deferred refurbishment was a result of constrained capacity which led to components operating at higher loads, to lack of maintenance windows and to increased failure rates; there was no formal refurbishment model and technical skills base was the weakest asset management link. The study advances a novel way of depicting root causes of suboptimal refurbishment in typically complex dynamic struc-tures using integrated systems thinking approach and applies analytical optimization tools, namely: Linear Programming (LP), metrics and N-1 contingency capability for refurbishment model for drilling deeper into causal typologies portrayed by systems thinking in order to solve optimization problems. A Total Refur-bishment Process model is advanced to replicate refurbishment decision structures for long term sustainability of industries as validated by industries studied.
\end{abstract}

Index Terms-Integrated systems thinking, N-1 contingency capability for refurbishment, metrics, asset management tools, Malawi, South Africa.

\section{NOMENCLATURE}

$\begin{array}{ll}\text { AM } & \text { Asset Management. } \\ \text { BSC } & \text { Balanced Score Card. } \\ \text { CAPEX } & \text { Capital Expenditure. } \\ \text { CBM } & \text { Condition Based Maintenance. } \\ \text { CDF } & \text { Customer Damage Function. } \\ \text { ESCOM } & \text { Electricity Supply Corporation of Malawi. } \\ \text { FMECA } & \text { Failure Mode Effect and Criticality Analysis. } \\ \text { LP } & \text { Linear Programming. } \\ \text { OPEX } & \text { Operating Expenditure. }\end{array}$

Manuscript received June 08, 2010; revised February 20, 2011; accepted March 20, 2011. Date of publication May 19, 2011; date of current version August 24, 2011.

B. O. Mkandawire is affiliated with Faculty of Engineering, University of Malawi, Blantyre, Malawi (e-mail: burnemkanda@hotmail.com).

N. M. Ijumba is affiliated with the University of KwaZulu-Natal, Durban, South Africa.

H. Whitehead is with Ethekwini Electricity, Durban, South

Africa. Digital Object Identifier 10.1109/JSYST.2011.2148790

\author{
PESTEL Political, Economic, Social, Technical, \\ Environmental and Legal. \\ PM Preventive Maintenance. \\ RCM Reliability Centred Maintenance. \\ TRPM Total Refurbishment Process Model.
}

\section{INTRODUCTION}

\section{A. Study Motivation and Systems Concepts}

\section{$\mathbf{T}$}

HIS study was carried out in South Africa and Malawi. It was triggered by empirical shortfalls in maintenance and refurbishment timing within the electric power sector in

Malawi. It applies systems thinking for a holistic view of maintenance and refurbishment within asset management systems based on case studies from largest Malawian and South African electric utilities whilst drawing some parallels from other industries. The novelty of this study is that it uses systems thinking to depict root causes of suboptimal refurbishment and applies linear programming as an analytical optimization tool to collate data for improvement. Systems thinking is a conceptual frame-work, a body of knowledge and tools developed to make full patterns clearer so as to help change them effectively [1]. Sys-tems thinking utilizes model elements to consider the compo-nential, relational, contextual and dynamic elements of interest [2]. It is about holism. The opposite of systems thinking is re-ductionism [3]. Maintenance and refurbishment systems exist within designed systems. These systems are emergent and hier-archical [3], [4]. Emergent properties not possible to detect by analysis should be possible to define by a holistic approach, that is, the systems thinking approach [4], [5]. The hierarchical characteristic of refurbishment within asset management (AM) is as shown in Fig. 1.

Refurbishment is a tactical asset renewal strategy/option/process and a means to achieving asset management (AM) optimization goals. Viewed broadly, AM consist of four stages that are depicted in Fig. 1, namely: setting business/mission objectives which identify and prioritize opportunities; constructing a strategy and tactical plans; injecting processes,

systems, technology, and resources; and measuring results in form of reliability or predictable/predictive capacity [6, p. 3]. Therefore, as a process, refurbishment falls under processes/systems of AM system. In terms of hierarchy, AM 


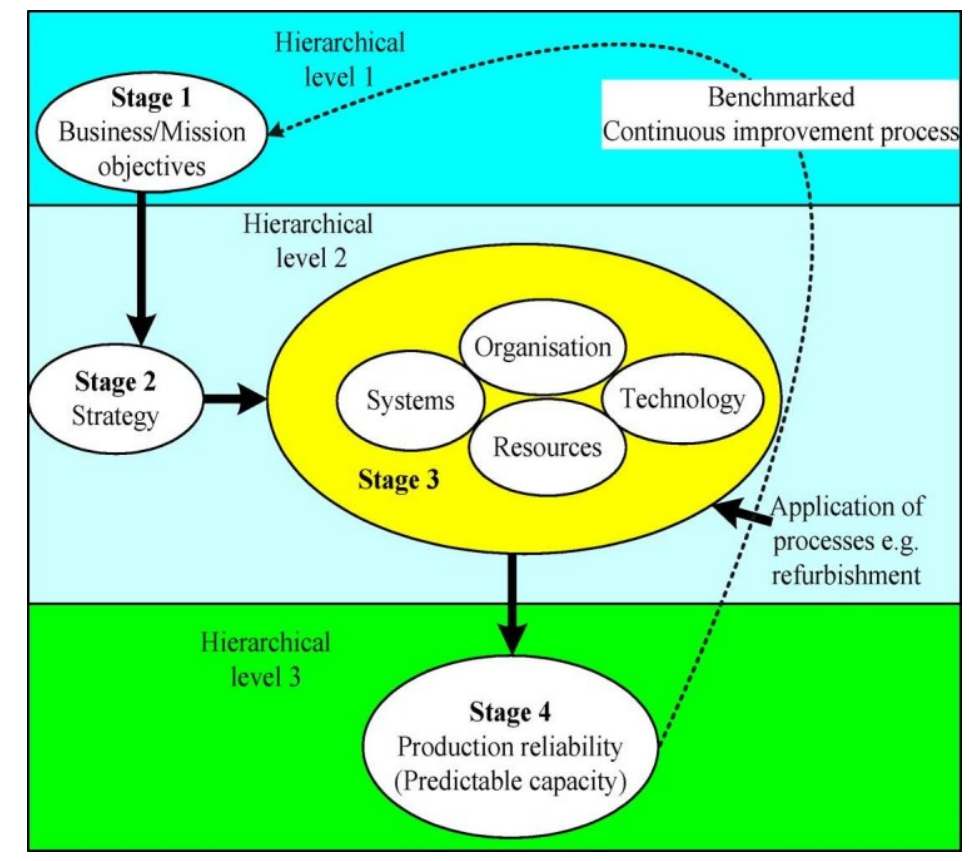

Fig. 1. Hierarchical nature of refurbishment process within asset management processes (adapted from [6, p. 13]).

system has three hierarchies and refurbishment falls in the second hierarchy as shown in Fig. 1. Fig. 1 confirms what Campbell and Reyes-Picknell [7] also advanced that strategy is the overarching element of AM processes as outlined by Stage 2 in hierarchical level 2 of Fig. 1. "Continuous improvement (CI) closes the feedback loop in Fig. 1 but that works if an organization is already a world leader; otherwise it is a terrible and disastrous idea if it is far behind the world standard" [6, p. 13]. To be effective, CI must be properly benchmarked.

Case studies may be used to establish causal linkages [8] and the vast body of knowledge may be used to model the causal relationships (linkages) [9].

Skyttner [5] advances that the systems thinking approach incorporates several central principles, namely: interdependence of objects and their attributes; holism, whereby emergent properties not possible to detect by analysis should be possible to define by a holistic approach; systemic interaction resulting in some goal; transformation of inputs into outputs to obtain goals; entropy (system disorder or randomness); regulation (feedback) for predictable system operation; hierarchy (smaller subsystems making complex wholes); differentiation (special-ization); Equifinality (convergence), which means alternative ways of attaining the same objectives; and multifinality (diver-gence) which means attaining alternative objectives from the same inputs [5].

\section{B. Engineering and Systems Thinking}

Refurbishment projects, like new projects, portray engineering and socio-technical aspects hence they display dynamic, transient, noncyclic, nonrepeating phenomena hence application of systems thinking is viewed as a valuable approach to solving refurbishment optimization problems. The field of systems thinking is not new but its application to engineering systems is relatively rare. Systems thinking theory originates from systems dynamics which was first propounded in 1956 by Professor Jay Forrester [9] who published the first work on system dynamics theory [10]. Professor Forrester forms the foundation of other systems thinkers of modern time like [1], [4], [5], and others.

1) Holism Versus Reductionism: Engineering systems models have been built from available knowledge about the separate components [9] which is a mechanistic approach or reductionism [3]; whereas economic systems models have often been constructed working backwards from observed total system results [9] which is a holistic approach or holism [3]. The reductionism works from top to bottom, it simpli fies by breaking a problem into smaller components whereas holism or systems approach works from bottom upwards, it simplifies by considering the environment where the problem exists [3]. Thus application of holistic, systems thinking approach can be used to eliminate the deficiencies of the mechanistic approaches that are inherent in analytical approaches to solving problems in refurbishment projects and maintenance processes. A multidimensional, integrated approach to asset management should apply tools such as value engineering, Life Cycle Costing (LCC), Reliability Centred Maintenance (RCM), and Risk Based Inspection (RBI) and must portray six attributes [11]. First, it must be holistic, that is, looking at the big picture by integrating all aspects of the assets (physical, human, financial, information, and intangible) rather than a compartmentalized approach. Second, it must be systematic: employing a me-thodical approach, promoting consistent, repeatable decisions and actions, and providing a clear and justifiable audit trail for decisions and actions. Third, it must be systemic: considering the assets as a system and optimizing the system rather than optimizing individual assets in isolation. Fourth, it must be risk-based: focussing resources and expenditure, and setting priorities appropriate to the identified risk and the associ-ated cost/benefits. Fifth, it must be optimal: establishing the 


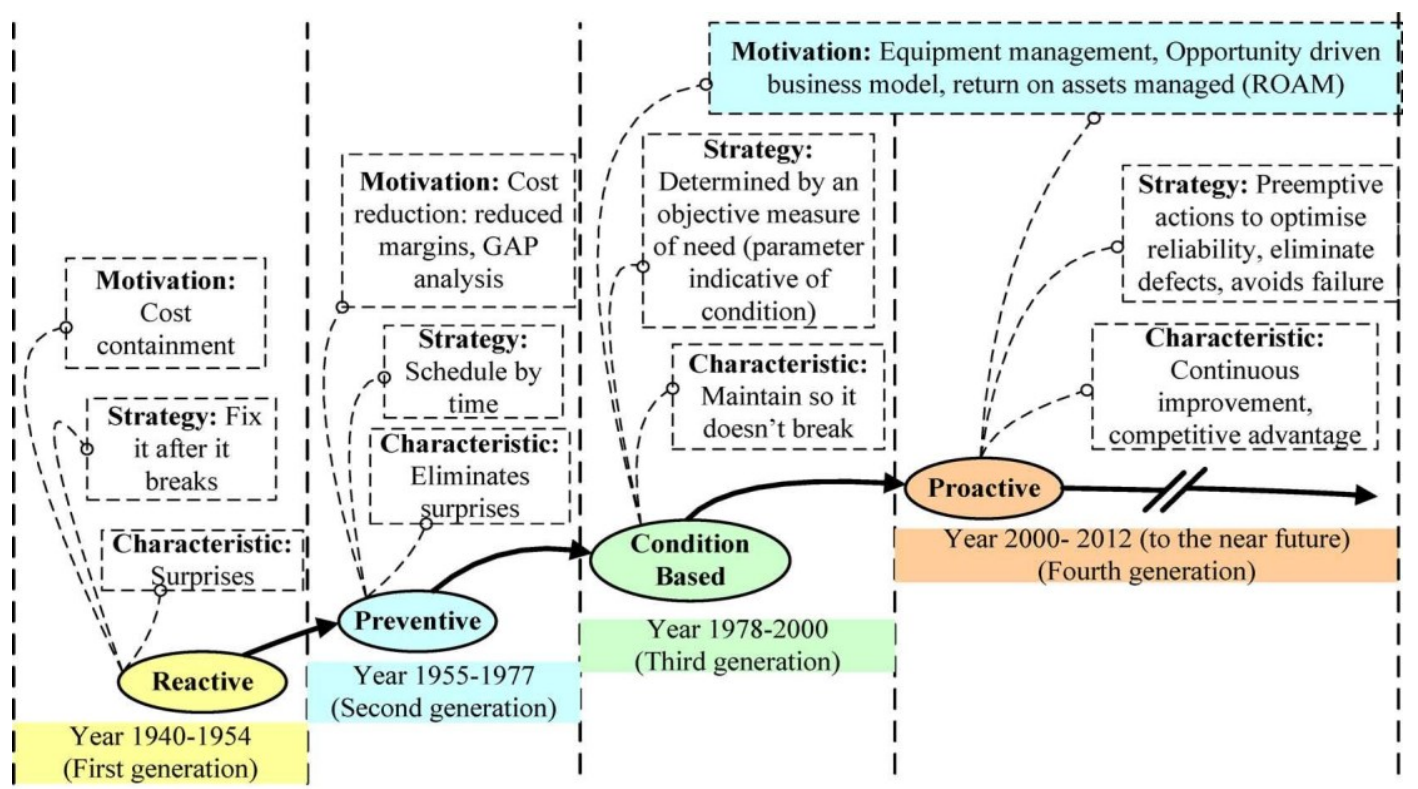

Notes to symbols and notations used: Dotted arrows and boxes show characteristics, strategies and motivations of the practices; whereas solid lines and oval shapes show the practices employed in asset management.

Fig. 2. Evolution of Equipment Management practices as inspired by [6, pp. 19-53] and [20, pp. 2-5].

optimum compromise between competing factors such as performance, cost and risk associated with the assets over their life cycles. Finally, it must be sustainable: considering the potential adverse impact to the organization in the long term of short term decisions aimed at quick wins. The integrated systems thinking is phenomenal to systems engineering. "Systems engineering has led to related practices and standards that can be used in the lifecycle management of complex systems" [12].

2) Merit of Integrated Systems Thinking Approach: Inte-grated systems thinking for refurbishment applied in this study uses causal linkages to go beyond terotechnology concept that simply emphasized combination of engineering, finance, management and related activities in pursuit of economic life cycle costing and feedback on design related issues [4, pp. 202-206]. It caters for additional aspects such as socio-tech-nical issues, regulatory issues, chain cause-effect relationships, and overarching properties such as interdependence, holism, goal seeking, inputsoutputs and their transformations, entropy, regulation (feedback, not only on design and performance but also of the whole), hierarchy, differentiation, equifinality, and multifinality [5]; and emergent properties [3], [4].

A comparative study of refurbishment in shipping and construction industry [13] revealed results similar to what happens in the power sector [14]. It showed that there was very little evidence of formal or structured processes of managing risks and uncertainty [13]. Refurbishment projects are usually more risky than new projects [15] hence it is advanced that risk man-agement techniques that were formerly used in mission critical component design or in insurance, financial and project manage-ment should be used to assess the asset management process de-ficiencies [16]. Maintenance and refurbishment are socio- tech-nical aspects [17] and patterns of human social behavior have had implications on large structures and vast organizations [18]. Systems thinking is suitable for solving problems of that nature.
3) Overview of Current Practices: Asset Management (AM) is about optimal equipment management whereby a set of disciplines, methods, procedures and tools are used to optimize the Whole Life Business Impact of costs, performance and risk exposure [19]. Refurbishment is a means to achieving the optimization of the Whole Life Business Impact. Current asset management (AM) practices are opportunity driven aimed at optimization of returns on assets managed (ROAM). The practices have evolved from reactive approaches as outlined in Fig. 2 [6] where the time frames have been specified by Moubray [20]. Generally, AM encompasses the principles of Six Sigma, the Balanced Score Card (BSC), Reliability Centred Maintenance (RCM), Reactive or Breakdown Maintenance, Preventive Maintenance (PM), Condition Based Maintenance (CBM), Proactive Maintenance and financial prioritisation in the decision making process $[6, \mathrm{p} .53]$.

Moubray [20] groups the stages of evolution in generations as follows: The reactive period as the first generation, from 1940 to 1954; preventive (supported by systems planning and con-trolling work with computer aid) as the second generation, from 1955 to 1977; and condition based with hazard and reliability studies, Failure Mode Effect Analysis (FMEA), expert systems and team work as the third generation; from 1978-2000. Each stage in the process is proclaimed as the solution that makes previous approaches obsolete [6]. Exceptions to the foregoing generalization are: CBM, which was introduced to supplement rather than replace PM; and Total Productive Maintenance (TPM) and RCM, which were promoted as the "conclusive process" [6, p. 53] of the current practices. Current practices advocate condition based, proactive and probabilistic ap-proaches [6], [16] and [21] and constitute the fourth generation. A distinct paradigm shift in asset management practices shall signify a change to the next generation, the fifth generation. 
a) Weaknesses of current practices and need for systems thinking: Physical asset management (AM) combines concepts and ideas from equipment management practices to form an op-timal mix that best addresses mission, business, site [facility conditions] and cultural requirements [6]. Current practices are weak in that, in the process of combining the processes, they propagate a linear cause and effect chain which is reductionistic thinking; whereas systems thinking is strong in seeing interre-lationships and processes [1].

Systems thinking concept gives the ability to see a big picture-yet get into the details [22].

Authorities in the AM field, for example, BSI-PAS 55 [23] have developed models that are excellent for depicting AM boundaries and/or scope but the models falter in that they use continuous improvement as a feedback loop in the AM process. As it was shown in Section I-A, continuous improvement works effectively if the organization is already the world leader in everything it does [6, p. 13]. However, it can also be argued that whether you are a world leader or not in everything you do, continuous improvement is still meritorious provided it is suitably benchmarked.

Probabilistic techniques have proven to offer more benefits than current maintenance based techniques in terms of reliability [predictable capacity] [24] but the stochastic nature of the techniques means their accurate application depends on quality of data and requires a large population of assets for meaningful and valid analysis [21]. Furthermore, analysts tend to limit boundaries of analysis to reduce complexity [3] thus systems thinking is necessary to reinforce current reductionistic approaches.

The remedy to reductionistic tendency inherent in current practices is therefore advanced to be integration of current traditional reductionistic approaches, for collation of data for anal-ysis [3] with systems thinking concepts to see causal effects, interrelationships and processes of change for management rethink [1], [18], [22]. This is integrated systems thinking.

b) Modelling of physical asset life: Modelling of physical assets has to identify physical property of a component relevant for functioning of the component in the system, effects of ageing and maintenance; hence some kind of condition monitoring must be part of a model [21] as it has been applied in this study.

Schneider et al. [16] schematically described modelling of emergent properties for electricity distribution industry in Germany using causal loop diagram which is a systems view. Leveson et al. [25] carried out a study at National Aeronautics and Space Administration (NASA) based on systems thinking to model NASA's safety culture and to validate management changes in engineering systems; and further showed that models developed can be used in assessing risk and in carrying out root cause analysis (RCA). The study was based on the background that changes and protections instituted at NASA after the Challenger accident gradually degraded to the point where the same performance pressures and unrealistic expectations implicated in the Challenger accident contributed also to the Colombia loss. Effects of ageing or degradation can also help in conducting RCA [26] hence ageing effects have been included in the models.

\section{Methodological Approach AND Concepts}

\section{A. Reasons for Chosen Methodology}

Systems thinking theory was used to establish causal links by way of causal loops derived from case studies in South Africa and Malawi and surveys conducted in Malawi for validation. Case study research strategy may be used to explain causal links in real life interventions that are too complex for survey or ex-perimental strategies or when there is no clear boundary be-tween concept and phenomenon [9] as is the case with main-tenance concepts and delayed refurbishment phenomenon.

Statistical validations from entire populations are not necessary in case studies since case studies do not represent entire populations [27]. Garson [27] further postulates that case study research may be used as a stand alone approach, but it is more often recommended as part of a multimethod approach ("triangulation") to provide a longitudinal, cross-sectional, or other comparative perspectives. When theories are associated with causal typologies, at least one case which falls in each category should be selected [28]. In this research, the authors established causal links between refurbishment and tools, processes, techniques, industry drivers, operating characteristics and management decision structure. These constituted model variables.

Case study critics often argue that case study research can neither be replicated nor generalized [due to lack of clear units of analysis] [29]. However, "what make research replicable in ei-ther case study or experimental research are not the units of anal-ysis but whether the research has been theory driven" [27]. Furthermore, in case studies one is generalizing to a theory based on cases selected to represent dimensions of that theory [27]. For Systems thinking theory the dimension of greatest impor-tance is emergent properties of systems [3]. In this research, the dimension of concern is emergent properties of refurbishment system with its associated subsystems such as decision struc-tures, timing and maintenance. However, in this study, sample surveys were also conducted as part of a multimethod or trian-gulation research approach, not only to satisfy case study critics but also to provide generalizations, validation and reliability.

One of the most difficult questions in case study research is how to determine the appropriate number of case studies. The relative size of case studies does not matter because even a single case could be accepted as long as it establishes parameters and meets the intended objective [9], [27].

Both quantitative and qualitative research approaches were applied in this study. This triangulation method involved longitudinal single case study within a $132 \mathrm{kV}$ grid of Electricity Supply Corporation of Malawi (ESCOM), a $400 \mathrm{kV}$ grid for a North West business unit of Eskom power utility in South Africa, multiple case studies of ten South African and Malawian firms and sample surveys of thirty four Malawian firms. In ad-dition, implementation of asset management principles in the firms was considered; degradation mechanisms were studied to define repair and refurbishment intervals, [21], [24]. Further-more, life management processes and assessment tools were 
studied to optimize utilization of the remaining lifetime and to provide assurance of reliability for aged units [16], [30].

\section{B. Characteristics of Chosen Attributes and Variables}

The way the six industrial flow systems, namely: information, orders, materials, money, personnel, and capital equipment interlock to amplify one another and to cause change and fluctuation forms a basis for anticipating the effects of decisions, policies, organizational forms, and investment choices $[9$, p. 8]. Forrester [9] described fluctuations and amplifications as catalytic, oscillating, chaotic, and/or exponential behavior of varying orders of differential equations; whereas Skyttner [5] described it as entropy. These characteristics are phenomenal to industrial dynamics.

An industrial dynamics approach is useful for design of more effective industrial and economic systems and goals [9] and it was used to trace cause-and-effect information feedback loops that link decisions to resulting information changes in refurbish-ment and asset management systems. The motivation for the dynamic approach was based on premises that even with good knowledge of the individual parts of the system, our intuitive judgement is unreliable about how these systems will change with time [9]. Furthermore, industrial systems are constructed internally in such a way that they create for themselves many of problems that are contextual, relational and dynamic; and that are often attributed to outside and independent causes [2], [9], [18].

\section{Validity of the Chosen Model}

In this section, the critical role of systems thinking in design and improvements of industrial systems and in integration of processes and tools is highlighted. It is aimed at laying fundamental modelling principles for solving integration problems under "integrated systems thinking approach" that has been pro-posed.

Models have been widely accepted as a means of studying complex phenomena and are broadly categorized as physical (using physical devices) or abstract (using symbols and flow di-agrams) [9]. Abstract models can also be a written language or a thought process, a mental image or a verbal description in Eng-lish; or a mathematical model where mathematical symbols and equations are used [9]. With the above attributes of models, the model used in this study is best described as open, dynamic, abstract model designed to depict essential characteristics of re-furbishment projects and systems.

Validity of a chosen model is rated by the ability to depict dynamic complexity and not detail complexity [1], [18]. This can be achieved by relying less exclusively on statistics and formal data and making better use of the vast store of descriptive information; and looking less for prediction of specifi c actions in the future and more for enhancing the understanding of the inherent characteristics of the system [9]. Simulations with thousands of variables and complex arrays of details [mathematical correlations] can virtually distract us from seeing patterns and major interrelationships [1, p. 72]; henceforth they were avoided in this study. However, Linear Programming (LP) was used to collate data for analysis of optimized electricity network and/or generation capacity that would enable execution of refurbishment without imposing constraints on the network. Hence, reproduc-tive ability or the prediction of the behavior characteristic or pattern of the system (as opposed to specific action) was used to test the validity of the model and corporate objectives or goals were used to set the frame for deciding what the model should do as shown by Forester [9].

\section{Symbols and Conventions Used in Models}

Most modern industrial strategic management systems are dynamic systems as they keep changing and require managers to be flexible to the change [31]. Among other things, dynamic systems models should be able to describe any statement of cause-effect relationships that we may wish to conclude and be closely synonymous in nomenclature to industrial, economics and social terminology [9, p. 67]. Such nomenclature as ap-plicable to systems thinking must be able to communicate at-tributes such as compensating feedback, reinforcing feedback, balancing feedback, delays, and generic structures or archetypes [1]; hence they have been applied in this paper. Senge [1] de-scribes each of these attributes as shown below. First, compen-sating feedback exists when well-intentioned interventions re-sult in system responses that offset the benefits of the inter-ventions. Second, in a reinforcing feedback system small ac-tions can grow into large consequences such as growth of a product from word of mouth. Third, balancing feedback repre-sents limits of reinforcing processes as it seeks stability through self correction that attempts to maintain some goal or to fill a gap (also see, e.g., Skyttner [5]). "Human decision makers often act contrary to balance: they cut back staff to lower cost and remain within budget only to find that the remaining staff are overworked and they engage consultants at higher cost" [1, p. 84]; and "only to discover that the knowledge and experience necessary to safely and effectively perform vital tasks had been irretrievably lost" [6, p. 42]. Fourth, according to [1], [9], and [10], delays exist when the effect of one variable on another takes time. Delay is represented by two cross hatch lines or by valve symbols (see, e.g., Section III). Fifth, there are also certain generic or systemic structures or system archetypes [1]. They re-veal areas where there is leverage in facing difficult challenges and help see the leverage in the associated structures [1]. Some examples of archetypes are: limits to growth (limits need to be removed for success), shifting the burden to external interven-tions instead of enhancing the capabilities of the host system to solve its own problems, and dependence on outside contrac-tors rather than training own staff [20]. Moubray [20] described an archetype on Reliability Centred Maintenance (RCM) im-plementation as "shifting the burden," that is, where external consultants are left to implement RCM entirely on their own and it becomes the cause of failure of most RCM programmes. This provides leverage for change as it depicts what is typical of power utility companies where most maintenance and refur-bishment jobs are contracted out and leads to shortage of skill by the host company. Other symbols used in systems thinking models have been provided by [1], [9], [25] and the same have been applied in this paper as follows: an $S$ is the same as a plus

$(+)$, signifying that when an independent variable changes the value of the dependent variable on the arrow end will be above what it initially was; an $O$ is the same as a minus $\left(\_\right.$, signifying 


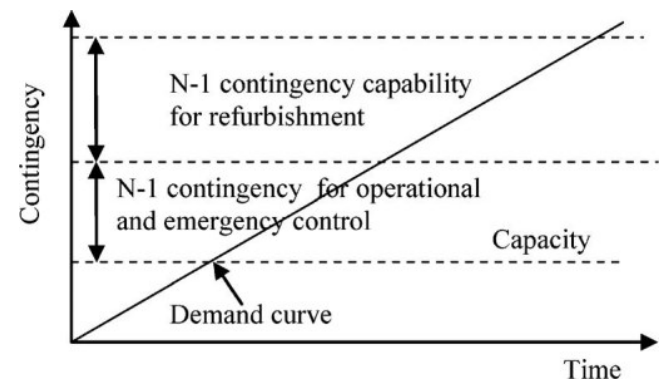

Fig. 3. N-1 contingency capability for refurbishment.

that when an independent variable changes, the dependent vari-able will be less than what it initially was; a $B$ within a curved arrow represents balancing feedback; and a $R$ within a curved arrow represents reinforcing feedback. These symbols can be seen in Section III.

\section{E. Optimization Model}

As stated earlier, systems thinking helped to see the big picture of suboptimal refurbishment causes but Linear Programming (LP) was used to go deeper into solving optimization problem, that is, dealing with capacity constraint. Metrics and a Balanced Score Card (BSC) were used for benchmarking because control is impossible without measurement (see, e.g., results in Section III). The $N_{-1}$ contingency capability for refurbishment can increase system security beyond the operational $N \_1$ contingency level so that assets can un-dergo refurbishment shut downs whilst ensuring continuity of supply to customers. A simple linear demand model is used for projecting demand growth with time in order to trigger refurbishment in time as outlined in Fig. 3.

For the $N \_1$ contingency capability for refurbishment being advanced, the objective function is defined as to find capacity $x_{1}$ follows:

plus reserve margin $x_{2}$ that optimizes $x_{1}+x_{2}$; expressed as

$$
f(x)=c_{1} x_{1}+c_{2} x_{2} .
$$

Optimization problem has duality in that as one objective function is minimized (for example, costs), the other is maximized (for ex. profits). In this case the function in (1) is minimized, as follows:

$$
\begin{gathered}
f=\sum_{j=1}^{n} c_{i} x_{j} \rightarrow \min \\
\text { Subject t } \bullet \sum_{i=1, \ldots, m ; \quad \boldsymbol{a}_{i j} x_{j} \leq \boldsymbol{b}_{i}} \quad j=1, \ldots, n ; \quad x_{j} \geq
\end{gathered}
$$

$x i \geq 0$ since capacity cannot be zero, where $c_{i}$ represents the market prices, $x i$ the control variable or the quantity produced, and $a_{i} i$ the coefficient representing a constraint.

In practice, multiple decision or control variables exist in either refurbishment or power generation. For instance, type and location, nature of capacity expansion and time of investment may result in different marginal costs for different capacities and reserve margins: $\mathrm{x} 1 \mathrm{X} 2 \mathrm{X}$. Thi $\S_{1}$ would lead to a set of simultaneous inequalities, hence (1)-(3) take the form of (4)(6) as follows:

$$
\begin{aligned}
& a_{11} x_{1}+\boldsymbol{a}_{12} x_{2}+\boldsymbol{a}_{1 n} x_{n} \leq \boldsymbol{b}_{1} \\
& a_{21} x_{1}+\boldsymbol{a}_{22} x_{2}+\boldsymbol{a}_{2 n} x_{n} \leq \boldsymbol{b}_{2} \\
& a_{m 1} x_{1}+\boldsymbol{a}_{m 2} x_{2}+\boldsymbol{a}_{m n} x_{n} \leq \boldsymbol{b}_{n n} .
\end{aligned}
$$

In matrix form, (4)-(6) can be expressed as

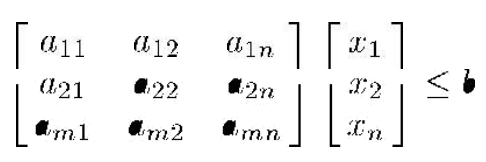

where

$$
b=\left[b_{1} ; \boldsymbol{b}_{2} ; \ldots \boldsymbol{b}_{m}\right] .
$$

Alternatively, the matrix form of the objective function is as follows:

$$
\begin{aligned}
& f=\underline{c x} \rightarrow \min \\
& \text { Subject tø : } \boldsymbol{A} \underline{\underline{x}} \leq \boldsymbol{b} \text {; } \\
& -\geq
\end{aligned}
$$

where $A$ is coefficient matrix of production constraints such as conversion, transportation/transmission, distribution, and allocation; $x$ is a vector of control variables; and $b$ is a vector of right hand side of constraints representing capacity or resource restrictions. The function $f$ can then be represented as $f_{T} x$ or $f$ $* x$ and evaluated using the generalized simplex method of LP [32] with MATLAB tool box as follows:

$$
\begin{gathered}
A \cdot x \leq b \\
\min _{x} f^{T} x \text { subject t } \bullet \text { Aeq } \cdot x=\text { beq } \\
1 \mathbf{b} \leq x \leq \mathrm{ub}
\end{gathered}
$$

where $\Lambda \mathrm{eq}$ is a matrix of the left hand side of the equality con-straints and beq is a vector of the right hand side of equality constraints such that $\Lambda \mathrm{e} q x=\mathrm{beq}$ satisfies the equality con-straints; $\mathrm{lb}$ and $\mathrm{ub}$ are lower and upper bounds of $b$, which also de fine the bounds of $x$. MATLAB algorithms that solve (11) are as shown in (12)-(13):

$$
x=\text { limpreg }
$$

which solves minf $f_{* x}$ such that $A_{*} \leq b$. Furthermore

$$
x=\operatorname{linpr\bullet g}(f, \mathbf{A}, \mathbf{b}, \mathbf{A} \text { eq, beq, lb, } u \mathbf{b})
$$

which defines a set of lower and upper bounds on control variable, $x$, so that $\mathrm{lb} \leq x \leq \mathrm{ub}$. Prior to optimization, the al-

gorithm finds a basic feasible solution by solving an auxiliary piecewise LP problem, where the objective function, $f(x)$ is reformulated as a penalty (constraint) function, $P$, and is given as

$$
P=\sum_{j} \boldsymbol{P}_{j}\left(x_{j}\right)
$$

where $P(x)$ measures level of violation of lower and upper bounds. $P_{j}$ is defined by

$$
P_{j}\left(x_{j}\right)=\begin{array}{ll}
x_{j} \quad u_{j} & \text { if } x_{j}>u_{j} \\
\bullet & \text { if } l_{j} \leq x_{j} \leq u_{j} \\
l_{j}-x_{j} & \text { if } l_{j} \geq x_{j}
\end{array}
$$


TABLE I

Application of Maintenance Strategies IN 34 SELECTED MALAWIAN FIRMS

\begin{tabular}{|l|l|}
\hline \multicolumn{1}{|c|}{ Maintenance strategies applied } & \% scores \\
\hline Time Based Maintenance (TBM) & 75.76 \\
\hline Corrective Maintenance (CM) & 27.27 \\
\hline Total Productive Maintenance (TPM) & 8.82 \\
\hline Condition Based Maintenance (CBM) & 6.06 \\
\hline Other strategies (Run to failure) & 6.06 \\
\hline Reliability Centred Maintenance (RCM) & 0.00 \\
\hline
\end{tabular}

Thus, the optimization problem is a reformulated auxiliary problem expressed as follows:

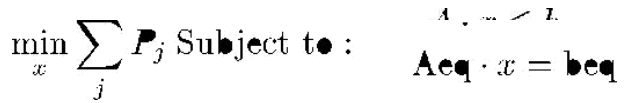

where $\Lambda \mathrm{eq}$ and beq are as explained under (11).

\section{RESUltS AND ANALYSIS}

Application of systems thinking in the study helped to establish a landscape that revealed causes of convergence, divergence, and disturbances in asset management (AM) decision structures pertaining to refurbishment. The causal typologies that are revealed can help improve decision processes in asset management in the electric power industry. Survey and case study results showed that $66.7 \%$ and $100 \%$ of firms surveyed and case studied respectively indicated that deferred or delayed maintenance and refurbishment were caused by constrained capacity as firms failed to timely shut down their plant for maintenance and refurbishment. It was shown that high dependence on external contractors to carry out refurbishment in power sector drained technical skills of host institutions, this, as stated by [20] is "shifting the burden". Hence capacity constraint and high dependence on contractors are archetypes in refurbishment system as they provide leverage for change as advanced in literature review [1]. Furthermore, naturally occurring windows of opportunity were usually inadequate for carrying out meaningful refurbishment and it was hard to establish refurbishment scope. Survey results of thirty four firms showed a lack of pro-activity because of heavy dependence on time based maintenance as outlined in Table I.

This was validated by ten case studies in largest power utilities in South Africa and Malawi; in a large copper refinery, a large petrochemical industry and a large diamond mine in South Africa. The findings were corroborated by results from case studies from five largest processing industries in Malawi. Re-sults also showed that some metrics in use in industries were se-lected out of tradition without evaluating whether they were the best. For example, the power utility in Malawi and mining in-dustries in South Africa traditionally use Availability as a metric to measure reliability of their network assets and plant. De-merits of relying on Availability were validated by comparing Availability against generation indices namely: Loss Of Load Expected (LOLE) and Loss Of Energy Expectation (LOEE). LOLE is the average number of days where the daily peak de-mand is expected to exceed the available generation capacity:

$$
\mathrm{L} \bullet \mathrm{LE}=\sum_{i=1}^{n} \boldsymbol{P}\left(C_{i}-L_{i}\right)[\text { ays } / \text { periød }]
$$

TABLE II

Comparing Availability as a Metric Against LOLE and LOEE

\begin{tabular}{|c|c|c|c|l|}
\hline $\begin{array}{l}\text { Power } \\
\text { Station }\end{array}$ & $\begin{array}{c}\text { Availabi } \\
\text { lity (\%) }\end{array}$ & $\begin{array}{c}\text { LOLE } \\
\text { (Days) }\end{array}$ & $\begin{array}{l}\text { LOEE } \\
\text { (MW) }\end{array}$ & $\begin{array}{l}\text { Unit } \\
\text { capacities }\end{array}$ \\
\hline A & 98.01 & 2.344 & 0.0987 & $8 \times 3 \mathrm{MW}$ \\
\hline B & 93.47 & 0.103 & 0.0215 & $20 \times 5 \mathrm{MW}$ \\
\hline C & 97.74 & 0.051 & 0.1926 & $25 \times 2 \mathrm{MW}$ \\
\hline D & 82.84 & 17.407 & 4.90597 & $32 \times 2 \mathrm{MW}$ \\
\hline
\end{tabular}

where $C_{i}=$ available capacity $\bullet$ day $i ; L_{i}=$ forecastpeakondayi: $P\left(C_{i} L_{i}\right)=$ probability of loss of load on day $i$. The probability of loss of load on day $i$ is obtained from the capacity outage cumulative probability table. LOEE is the expected energy not supplied by the generation system when the load demand exceeds the available generation capacity. It is also known as EUE (Expected Unsupplied Energy):

$$
\mathrm{L} \bullet \mathrm{EE}=\sum_{i=1}^{n} E_{k} \boldsymbol{p}_{k}
$$

where $k$ is a subscript representing magnitude of capacity outage, $\mathrm{O}_{\mathrm{k}}: p_{k}=$ probability of capacity outage corresponding to $O_{k}: E_{k}=$ energy curtailed by a capacity of magnitude

$O_{k}$. For example, from Table II, Availability of $98.01 \%$ for a power plant would generally be considered world class [6, p. 99], but when analyzed, it resulted in a LOLE of 2.344 days/year and a LOEE of 0.0987 MW per year. Comparatively, Availability of $93.47 \%$ for another power plant, which is not in the world-class category, resulted in better values of LOLE of 0.1029 days and LOEE of $0.0215 \mathrm{MW}$ per year than a plant with $98.1 \%$ Availability. So it is clear that although Availability of $98.01 \%$ is better than $93.47 \%$, the later resulted in better or more desirable values of Loss Margin. The difference is due to varying system capacity configurations which could not be detected by Availability. The best metrics should therefore show the Loss Margin (LM).

A systems view of delayed refurbishment established from the results is outlined in Fig. 4. It shows that increase in oper-ating intensity leads to components operating at higher loads, to increase in deferred maintenance and refurbishment which in turn reduces refurbishment efforts and deteriorates asset con-dition. Training improves skills, motivates, and retains staff, which in turn improves asset condition. Furthermore, effects of increased operating intensity are delayed (shown by valve symbol) but they eventually lead to accelerated ageing and de-terioration of asset condition, phenomenal to an overshoot ef-fect; improved asset condition improves performance which in-creases revenue and creates good public image which increases number of satisfied customers. Increased number of satisfied customers creates demand which increases revenue for acquisi-tion of resources for OPEX and investment/CAPEX and even-tually improves maintenance and refurbishment effectiveness; on the other hand, demand has also a balancing effect: it cre-ates pressure on operating intensity (hence the balancing loop on the lower right of Fig. 4) which tends to increase operating intensity thereby overloading assets and leading to failure. The cycle goes on and on in that way. Any point can be considered as a starting point in the cycle but capacity constraint is the main 


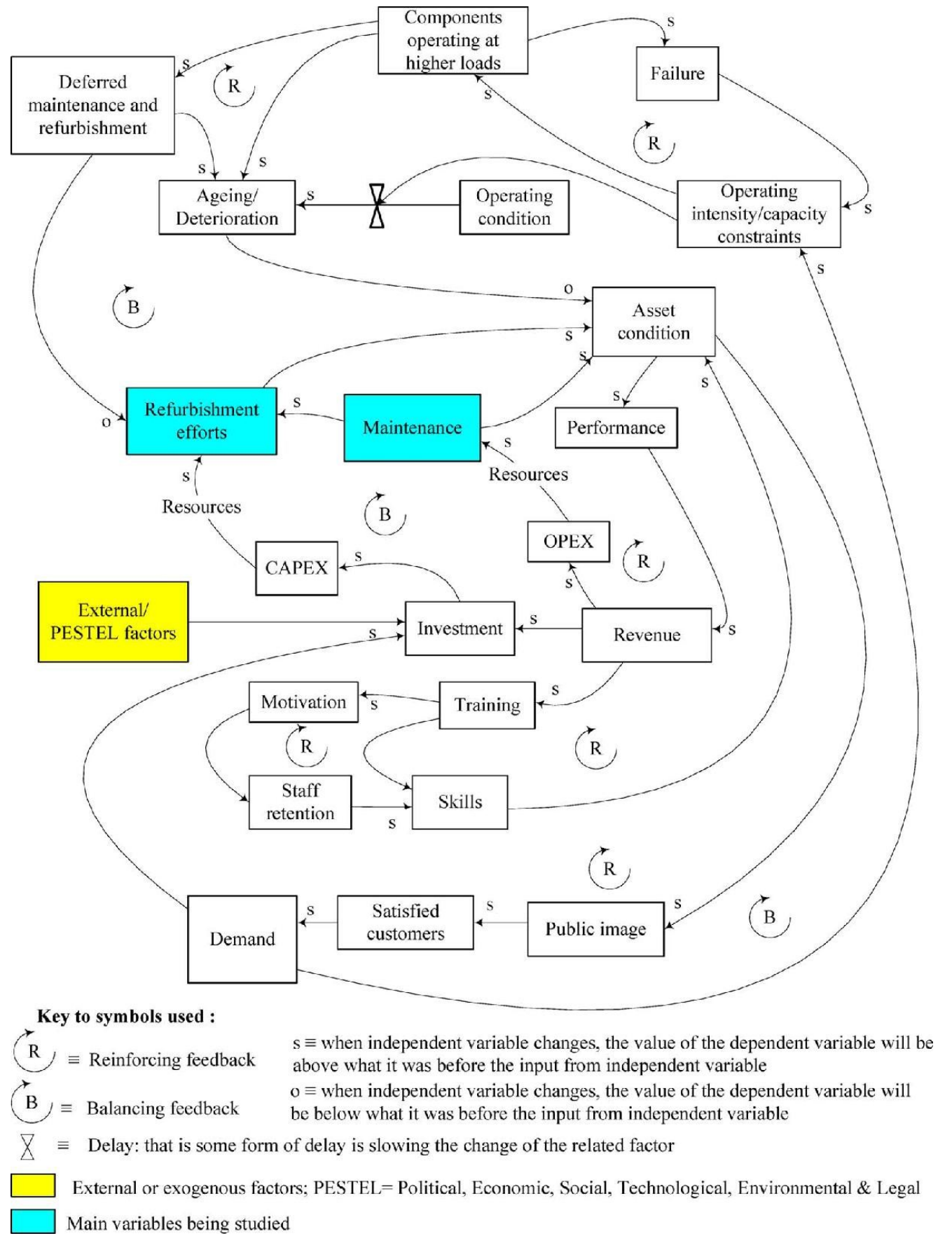

Fig. 4. Causal loop diagram of typical interrelationships in refurbishment and maintenance systems.

causative agent (an archetype) in suboptimal refurbishment. The sugar processing industry is employing stepwise refurbishment to overcome the capacity constraint problems where, for ex-ample, a capital intensive agitator would be repaired in five stages, of short time spans (short shut down times), over a pe-riod of five years. This enables them to reduce the Loss Margin (LM) and Customer Damage Functions (CDF) such as public outrage.

Fig. 5 outlines results of a Balanced Score Card (BSC) which reveals that technical skills- base, which was viewed by $52 \%$ of surveyed firms as the most important success factor for refur-bishment, was surprisingly the least developed aspect of asset management (AM).

\section{Discussion OF ReSUlts}

1) Significance of Results: Research showed that poor timing of refurbishment is an optimization problem that can be corrected by contingency management and capacity planning. Since this type of contingency is different from the $N-1$ contingency for operations, it has been termed $N \_1$ contin-gency capability for refurbishment model. The model, utilizing linear interpolation of demands and capacity as well as Linear Programming (LP), has been advanced to help plan and opti-mize refurbishment. Industries fail to optimize refurbishment due to capacity constraints which subject network assets to high stress when some of them are taken out for refurbishment. 


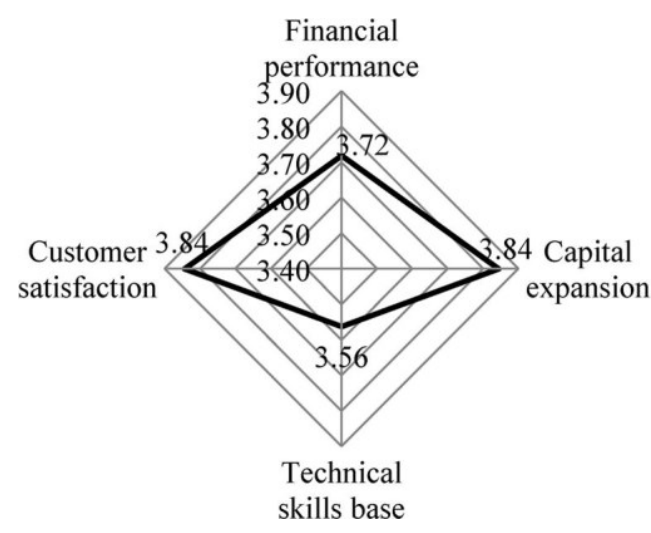

Fig. 5. A Balanced Score Card (BSC) showing skills base as weakest asset management link.

Therefore, it has been deduced that capacity expansion should be integral with refurbishment initiatives which is similar to what [32] showed. Stepwise refurbishment has been shown to be an effective means of executing refurbishment when faced with capacity and/or fi nancial constraints. The whole process of integrating factors, strategies and philosophies in order to optimize refurbishment has been assembled into a model outlined in Fig. 6.

In Fig. 6, solid single sided arrows show single directional flow of decision processes whereas solid double -sided arrows show direction of flow of two-way, concurrent decision pro-cesses. Furthermore, dotted single-sided arrows show one directional feedback processes whereas dotted double-sided arrows show two- way, concurrent feedback processes. The model, inspired by research, represents a methodical refurbish-ment decision process consisting of blocks numbered from 1 to 9 . The following notations apply to Fig. 6: LCMP is Life Cycle Management Plan; RSLP is Residual Service Life Prediction; AM is Asset Management; TPM is Total Productive Maintenance; ERP is Enterprise Resource Planning; EAM is Enterprise Asset Management; RCM is Reliability Centred Maintenance; CMMS is Computerized Maintenance Manage-ment System; CPM is Corporate Performance Management; CBA is Cost Benefit Analysis; BSC is Balanced Score Card; AMP is Asset Management Plan; ODM is Optimized Decision Making; TBL is Triple Bottom Line; and LP is Linear Pro-gramming. Block \#1 represents basic AM. Block \#2 represents Top-Down Bottom-Up techniques (\#2 a and $2 \mathrm{c}$ ) [17] and middle enhancers/lubricators (\#2 b) [19] needed to formulate maintenance strategies and to execute maintenance effectively. Block $\# 3$ is needed to understand plant operating characteris-tics; block \#4 is for aligning assets with corporate objectives; \#5 is Optimized Decision Making (ODM) for end of life de-cisions and cost/risk management; \#6 is $N \_1$ contingency for refurbishment and linear programming to manage capacity constraints; \# 7 is budgeting which depends on true asset worth from \# 8; and block \# 9 is measurement of need as a key input to basic asset management $(\# 1)$, operating characteristics (\#2 a) and $N-1$ contingency management (\#6). All the blocks are integrated and constitute an optimized integrated systems thinking for refurbishment, the Total Refurbishment Process Model.
2) Strengths and Weaknesses of Systems Approach: It has been observed that the systems approach has formidable capa-bility to detect underlying causes of suboptimal refurbishment but it lacks the means for determining the magnitude of the sub-optimization problem such as system equations to quantitatively show effects of delays in carrying out decisions; and the way de-cisions interlock to amplify each other. For example, in a causal loop diagram on causes of suboptimal refurbishment (Fig. 4) it was shown that increase in the number of components oper-ating at higher loads led to deferred refurbishment. Future work should formulate equations to relate number of components op-erating at higher loads at say, time $x$ to those at time $y$ within a time interval delta $t \Delta t$ which is the solution-time interval

between evaluations of the set equations. Hence, if the current number of components at time $y$ is CHLy, then this number of components will be equal to components previously computed at time $x$, CHLx, plus the difference between components admitted at higher operating load regime, $\mathrm{C} A \mathrm{HL}$ and components relived from operating at higher load regime as a result of capital expansion or network strengthening, | 口L_I between time interval $\square$ to ; in time delta $\mathbf{I} \mathbf{\square I}$; mathematically:

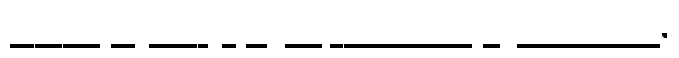

In this way, the amount of amplification of decisions or ac-tions carried out during refurbishment can be quantified; and their generic effect on refurbishment can be specified and ap-propriate counter measures can be formulated. Despite the cur-rent weaknesses, the systems thinking approach is still a valu-able tool for detecting the root causes of problems in complex systems, whereas analytical and quantitative approaches such as linear programming, metrics, Balanced Score Card (BSC) and statistics can be incorporated as means of collating measurable data for solving specific problems established from the observed total systems results. Therefore, integrated systems thinking and $N \_1$ contingency capability for refurbishment helped to opti-mize return on assets. It also provided a formal model for repli-cating refurbishment decisions in industry as validated by the power, mining and processing industries studied. The triangula-tion (multimethod) approach made it possible to generalize case study results.

\section{CONCLUSION}

Systems thinking is an approach to holistically establish interrelationships and causation in dynamically complex structures thereby making clearer the requisite structures for componen-tial analysis. Integrated systems thinking established the root cause of suboptimal refurbishment process so that optimization problems observed from the total system results were solved using linear programming, metrics, and Balanced Score Card (BSC). $N_{-} 1$ contingency capability for refurbishment manage-ment model incorporating linear programming routines should be used to plan timely and optimal refurbishment by adding contingencies over and above the $N-1$ contingency for op-eration and emergency control. Network strengthening and ca-pacity planning and expansion should be integral with optimal refurbishment strategies. 


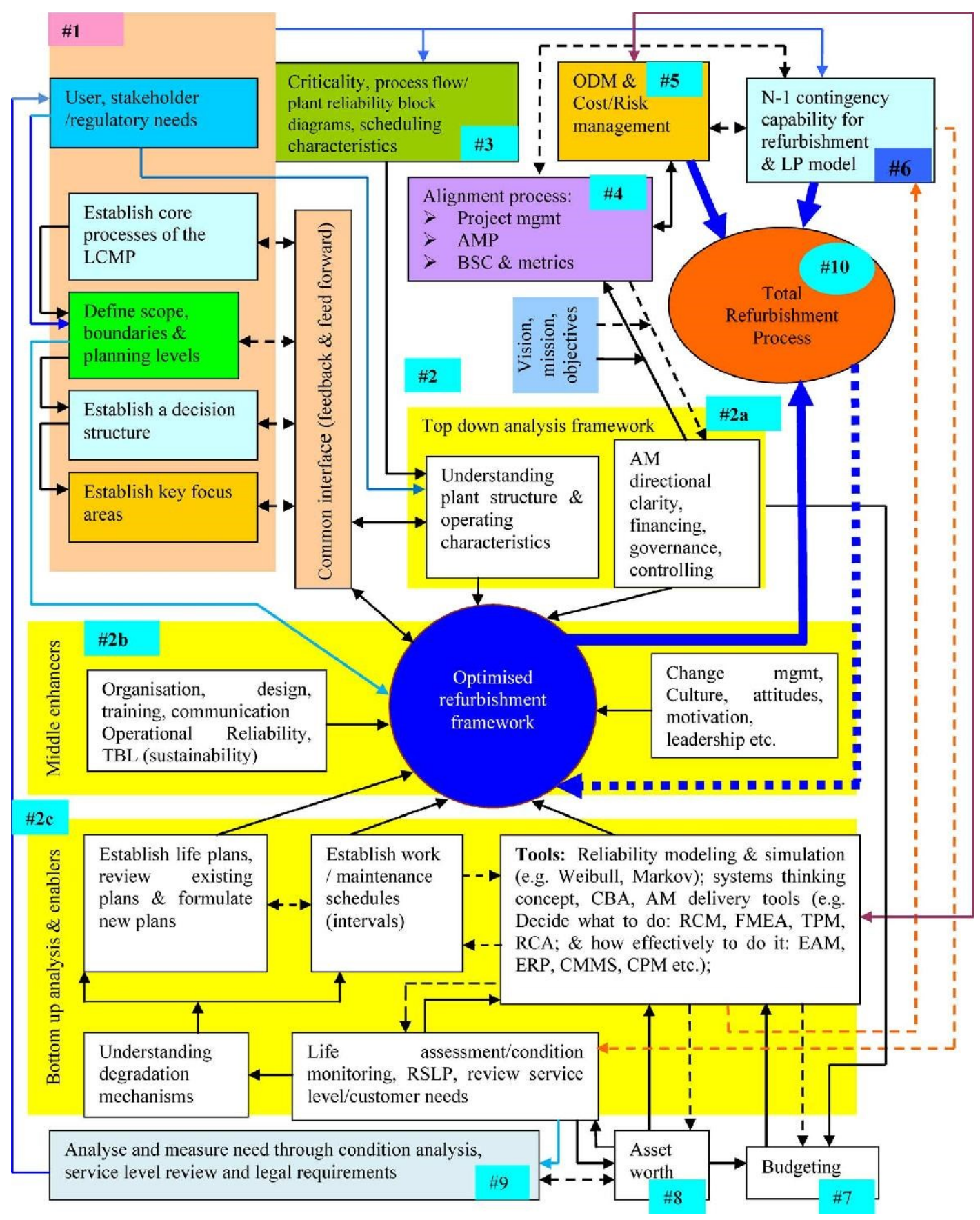

Fig. 6. Total Refurbishment Process Model: a systems view of refurbishment.

The novelty of the optimization model advanced in this study is that it applies systems thinking to depict root causes of suboptimal refurbishment; and applies linear programming as an analytical optimization tool to collate data for determining capacity that prevents violation of operational $N \_1$ contingencies when some network assets are taken offline for refurbishment. This study has shown that the prime cause of suboptimal refurbishment is failure by firms to shut down their facilities for refurbishment due to capacity constraints which force them to operate continuously as demonstrated by practical validations from ten case studies and thirty four statistical surveys of electrical, mining, process and manufacturing industries studied. It has been demonstrated that the model developed can be employed not only in the electric power sector but also in other operating industries which depend on long term performance of their physical assets for their sustainability. Incorporation of system equations in the causal loops in future will reveal not only causation but also magnitudes of amplifications of industrial flow systems in dynamic systems.

\section{ACKNOWLEDGMENT}

The authors are greatly indebted to the Technology and Human Resources for Industry Programme (THRIP) of South Africa for funding the study, to the management of Electricity 
Supply Corporation of Malawi (ESCOM), to the Eskom power utility company of South Africa and to Sasol (Secunda plant) for providing invaluable technical and professional support.

\section{REFERENCES}

[1] P. M. Senge, The Fifth Discipline: The Art \& Practice of the Learning Organisation. London, U.K.: Century Business, 1993.

[2] H. L. Davids and D. J. Nightingale, "Enabling systems thinking to accelerate the development of senior systems engineers," Syst. Eng., vol. 11, no. 1, pp. 1-14, 2008.

[3] D. White, "Application of a systems thinking to risk management: A review of the literature," Manag. Dec., vol. 33, no. 10, pp. 33-45, 1995.

[4] P. Checkland, Systems Thinking, Systems Practice, 2nd ed. Chichester, U.K.: Wiley, 1990.

[5] L. Skyttner, General Systems Theory: Problems, Perspective, Practice., Singapore: World Scientific, 2006.

[6] J. S. Mitchell, Physical Asset Management Handbook, T. H. Bond and N. Nodianos, Eds., 3rd ed. Houston, TX: Clarion, 2002.

[7] J. D. Campbell and J. V. Reyes-Picknell, Uptime: Strategies for Excellence in Maintenance Management. Portland, OR: Productivity Press, pp. 10-20, 158-164.

[8] R. K. Yin, Case Study Research, Design and Methods, 2nd ed. Thousand Oaks, CA: Sage, 1994.

[9] J. Forrester, "Systems Dynamics," Mass. Inst. Technology (MIT). Cambridge, 1961

[10] D. Aronson, Introduction to Systems Thinking Jan. 1996 [Online]. Available: www.thinking.net, [Online] Available:

[11] Publicly Acceptable Standard, , 2004, BSI Specification: BSI-PAS 55 for the optimised management of physical infrastructure assets.

[12] , H. B. Lawson and J. P. Wade, Eds., Systems Thinking and Systems Engineering: A Journey Through the Systems Landscape. London, U.K.: College Publications, 2010.

[13] C. Lee and C. Egbu, Matching Client Project Requirements With Refurbishment Project Team Knowledge. Glasgow, U.K.: Caledonian Univ. Press, 2006.

[14] W. H. Bartley, "Life cycle management of utility transformer assets," presented at the Conf. Breakthrough Asset Management for the Restructured Power Industry: The Hartford Steam Boiler Inspection and Insurance Company, Salt Lake City, UT, Oct. 10-11, 2002.

[15] C. O. Egbu, B. Young, and V. B. Torrance, "Refurbishment management practices in the shipping and construction industries-lessons to be learned," Building Res. Inf., vol. 24, no. 6, pp. 329-338, 1996.

[16] J. Schneider, J. Gaul, C. Neumann, J. Hogräfer, W. Wellßow, M. Schwan, and A. Schnetter, "Asset management techniques," Intl. J. Elect. Power Energy Syst., vol. 28, no. 9, pp. 643-654, 2006.

[17] A. Kelly, Maintenance Strategy. Oxford, U.K.: Butterworth-Heinemann, 1997.

[18] H. Petroski, Success Through Failure: The Paradox of De-sign. Princeton, NJ: Princeton Univ. Press, 2006.

[19] J. Woodhouse, Asset Management Processes and Tools. Newbury, U.K.: Woodhouse Partnership, 2001.

[20] J. Moubray, Reliability Centred Maintenance, 2nd ed. Oxford, U.K.: Butterworth-Heinemann, 1997.

[21] M. Schwan, K. H. Weck, and M. Roth, "Assessing the impact of maintenance strategies on supply reliability in asset management methods," in Proc. 40th CIGRE Session of August, 2004, paper C1-108.

[22] M. Ryschkewitsch, D. Schaible, and W. Larson, "The art and science of systems engineering," National Aeronautics and Space Administra-tion (NASA) Jan. 2009 [Online]. Available: http://www.nasa.gov/pdf/ 311198main_Art_and_Sci_of_SE_LONG_1_20_09.pdf

[23] J. Woodhouse, PAS-55-Asset Management: Concepts and Practice. Newbury, U.K.: Woodhouse Partnership, 2006.

[24] J. Endrenyi, Reliability Modelling in Electric Power Systems. New York: Wiley, 1980, pp. 251-254.

[25] N. G. Leveson, B. Barret, J. Carol, J. Cutcher-Grschenfeld, N. Durac, and D. Zipkin, Modelling, Analysing and Engineering NASA's Safety Culture In Phase 1 Final Report, Feb. 2004-Feb. 2005.
[26] M. Kemppainen, J. Scheibel, and R. Viswanathan, "EPRI-combustion turbine hot section life management," in $O M M I, 2002$, vol. 1, no. 2.

[27] G. D. Garson, Case Study Research Mar. 2, 2008 [Online]. Available: www.adizesgraduateschool.org/AGSPDF/casestudymgmt.doc

[28] W. Tellis, The Qualitative Report, 1997, vol. 3, No. 2.

[29] J. Hamel, S. Dufour, and D. Fortin, Case Study Methods. Newbury Park, CA: Sage, 1993.

[30] M. Perkins, L. Petterson, N. L. Fantana, T. V. Oommen, and S. Jordan, "Transformer life assessment tools with specific application to nuclear power station generator transformers," in Proc. Electrical Insulation and Electrical Manufacturing and Coil Winding, Cincinnati, OH, Oct. 26-28, 1999, pp. 685-690.

[31] S. Johnson, Who Moved my Cheese. Reading, U.K.: Cox and Wyman, 1998.

[32] G. B. Dantzig, A. Orden, and P. Wolfe, "The generalized simplex method for minimizing a linear form under linear inequality restraints," Pac. J. Math., vol. 5, no. 2, pp. 183-195, 1955.

[33] M. M. Belsnes, O. B. Fosso, and G. Warland, "Combining production and transmission system using relaxed constraints," presented at the The 14th PSCC, Jun. 24-28, 2002, Session 30, Paper 6, Sevilla, SINTEF Energy Research..

Burnet O'Brien Mkandawire received the B.Sc. degree in mechanical engineering from the University of Malawi in 1992 and the M.Sc. Eng. degree in electric power and energy systems from the University of KwaZulu-Natal (UKZN), Durban, South Africa, in 2008).

$\mathrm{He}$ is a Lecturer in automobile engineering at the Polytechnic College of the University of Malawi, which he joined in 2003. He worked as a Regional Engi-neer for Department of Plant and Vehicle Hire Organisation, Principal Engineer and Deputy Controller in the Ministry of Works in Malawi between 1992 and 2002. His field of interest is sustainable energy supply and management.

Mr. Mkandawire is a Registered Professional Engineer in Malawi (R.Eng.), a corporate member of the Malawi Board of Engineers and a Member of the Malawi Institution of Engineers (MMIE).

Nelson Mutatina Ijumba received the B.Sc. (Hons) M.Sc. (Salford), and Ph.D. degrees from the University of Strathclyde, U.K.

$\mathrm{He}$ is a Deputy Vice Chancellor responsible for research at the University of KwaZulu-Natal (UKZN), Durban, South Africa. He is a Full Professor in High Voltage Direct Current (HVDC) engineering. He worked as the Dean of Engineering before being promoted to the post of Deputy Vice Chancellor of the University of KwaZulu-Natal. He has published extensively in HVDC.

Prof. Ijumba is a Practising Engineer (Pr.Eng.) a Chartered Engineer (C.Eng.), a Registered Engineer (R.Eng.) in Tanzania and Kenya, and a member of the Institute of Electrical Engineers.

Howard Whitehead received the B.Sc. (Eng.) degree from University of South Africa and also holds an MBL (South Africa).

$\mathrm{He}$ is formerly Chief Executive Officer of Durban Municipality and is infrastructure management trainer for Institute of Municipal Engineers of South Africa (IMESA). His career spans from 1966 to 2006, where he started as an Engineer at Durban Municipality and rose through the ranks to head several de-partments, culminating to Executive Director of Electricity.

Mr. Whitehead is a Practising Engineer (Pr.Eng.), a Fellow of the South African Institute of Electrical Engineers (SAIEE) . He served as Chairman of Natal Branch Committee of SAIEE and President of Association of Municipal Electricity (AMEU). Currently, he is Honorary Vice President of the SAIEE and a Member and Chairman of the Governing Council of the Durban Technical College and the George Campbell Technical High School. He has extensively published reports and articles on Traffic Signalling, Electrification, Electricity Distribution, Restructuring, Tariffs and Pricing; and Prepayment Metering in South Africa. 